GRADIATION\&APPLICATIONS

ISSN 2466-4294 (online) | rad-journal.org

Vol. 3 | Issue 2 | pp. 88-90, 2018

doi: 10.21175/RadJ.2018.02.014

Short note

\title{
DETERMINATION OF CARBON-14 AND TRITIUM IN IRRADIATED REACTOR GRAPHITE*
}

\author{
Iurii Simirskii**, Alexey Stepanov, Ilia Semin, Anatoly Volkovich
}

National Research Centre "Kurchatov Institute”, Moscow, Russia

\begin{abstract}
In order to determine ${ }^{14} \mathrm{C}$ in irradiated graphite, a method based on the oxidation of the graphite in the oxygen flow was used. This method makes it possible to visually monitor the end of the process and simultaneously separate ${ }^{14} \mathrm{C}$ from ${ }^{137} \mathrm{Cs}$ and ${ }^{\circ} \mathrm{Sr}$, which interfere with its determination. This method was used to analyze irradiated graphite samples from the research reactor RFT (NRC Kurchatov Institute) and the RBMK Leningrad nuclear power plant. The concentrations of ${ }^{14} \mathrm{C}$ and ${ }^{3} \mathrm{H}$ in the irradiated graphite of the reactor RFT were insignificant, except for those in the active zone. In this zone, the concentrations of ${ }^{14} \mathrm{C}$ and $3 \mathrm{H}$ increased by more than two orders of magnitude up to $1 \mathrm{O}^{7} \mathrm{~Bq} / \mathrm{kg}$ that corresponded to their activation nature. ${ }^{137} \mathrm{Cs}$ and ${ }^{90} \mathrm{Sr}$ are the main radionuclides contaminating the RFT reactor irradiated graphite that reveals their crash origin. In the RBMK Leningrad nuclear

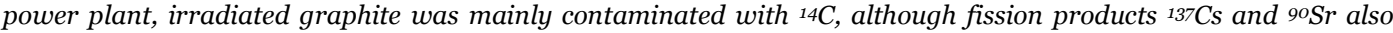
make a significant contribution.
\end{abstract}

Key words: Reactor graphite, oxidation in the oxygen flow, carbon-14, radionuclide contamination

\section{INTRODUCTION}

At the moment, there are 11 nuclear power units with RBMK reactors (4 of them at the Leningrad nuclear power plant) in Russia and, at the end of their function, the mass of irradiated graphite will reach 60 thousand tons. Thus, a special problem arises while dismantling uranium-graphite reactors: a need to deal with huge amounts of radioactive graphite products.

As a result of a prolonged neutron irradiation in the reactor graphite, impurities are activated and radionuclides with different half-lives are formed some with more than a thousand years. Special attention is paid to the long-lived $\beta$-emitting radionuclide ${ }^{14} \mathrm{C}\left(\mathrm{T}_{1 / 2}=5730\right.$ years $)$ and the biologically active beta-emitting radionuclide tritium $\left(\mathrm{T}_{1 / 2}=12.3\right.$ years).

The components of nuclear fuel and fission products also contribute to graphite contamination. The complex process of the formation of reactor graphite radionuclide contamination, which determines the level and composition of accumulated radioactivity, requires mandatory studies. These results are used to estimate the amount of radioactive waste and the dose loads during the dismantling of a uranium-graphite reactor.

\section{INVESTIGATION METHODS}

In order to determine ${ }^{14} \mathrm{C}$ in irradiated graphite, a method based on the oxidation of graphite in the oxygen flow is used. This method makes it possible to visually monitor the end of the process and simultaneously separate ${ }^{14} \mathrm{C}$ from ${ }^{137} \mathrm{Cs}$ and ${ }^{90} \mathrm{Sr}$ that interfere with its determination [1].

Graphite samples of 0.2-1.o g were oxidized at 850$900^{\circ} \mathrm{C}$ an oxygen flow. The formed ${ }^{14} \mathrm{CO}_{2}$ and $\mathrm{HTO}$ were collected in two successively located traps filled with a $20 \% \mathrm{NaOH}$ solution. $90-95 \%$ of ${ }^{14} \mathrm{CO}_{2}$ and $100 \%$ of HTO condensed in the first trap (Fig. 1).

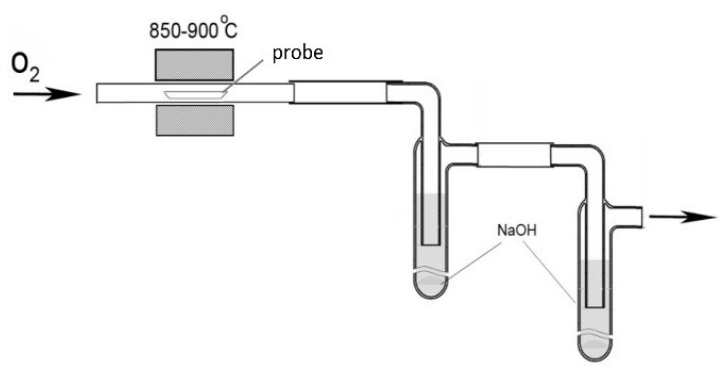

Figure 1. Device scheme for the graphite oxidation

\footnotetext{
* This paper was presented at the Sixth International Conference on Radiation and Applications in Various Fields of Research (RAD 2018), Ohrid, Macedonia, 2018.

simirskiy.yury@yandex.ru
} 
I. Simirskii et al., Determination of carbon-14 and tritium..., Rad. Applic., 2018, 3, 2, 88-90

Concentrations of ${ }^{14} \mathrm{C}$ and $3 \mathrm{H}$ were detected by the highly sensitive spectrometric complex SKS-07P-B11 with the liquid scintillator ULTIMA GOLD $\mathrm{AB}$ and calculated by the "Liquid Master" software. In cases of close concentrations of ${ }^{14} \mathrm{C}$ and ${ }^{3} \mathrm{H}$ in the sample, their simultaneous determination was possible (Fig. 2). In other cases, the concentration of $3 \mathrm{H}$ was determined after its isolation by distillation.

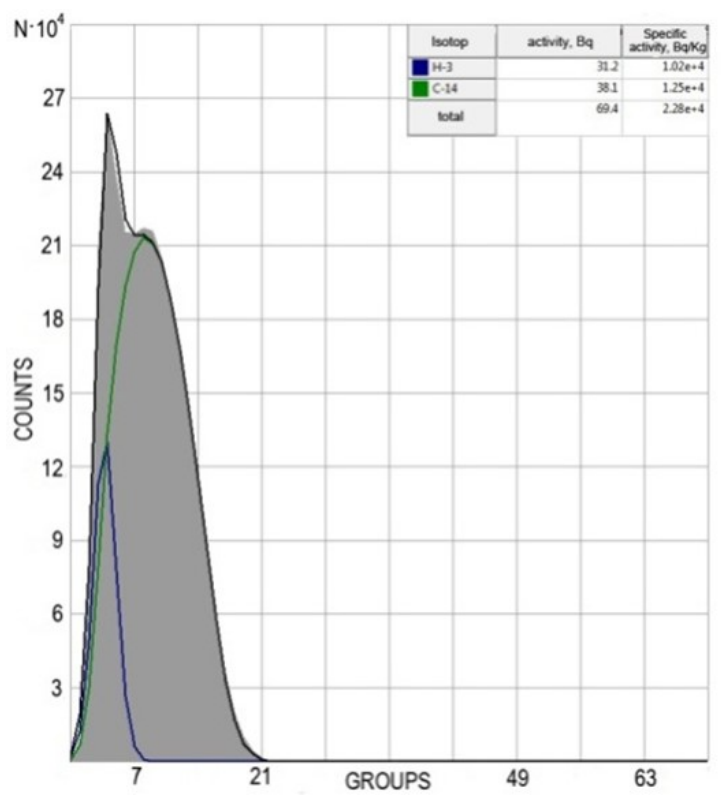

Figure 2. RFT graphite probe total spectrum of ${ }^{14} \mathrm{C}$ and $3 \cdot \mathrm{H}$

In case of accidents during the reactor function, nuclear fuel fission products make a significant contribution to radionuclide contamination of the reactor graphite. Therefore, ${ }^{137} \mathrm{Cs}$ and ${ }^{90} \mathrm{Sr}$ contamination in the reactor graphite need to be controlled simultaneously with the determination of ${ }^{14} \mathrm{C}$ and $3 \mathrm{H}$ concentrations. The concentration of ${ }^{137 \mathrm{Cs}}$ was detected by the spectrometric complex InSpector2000 of the Canberra Company that included a semiconductor detector using HP Germanium (GC4018). The analysis of the $\gamma$-spectrum was made by the GENIE-2000 software. The concentration of ${ }^{90} \mathrm{Sr}$ was detected by the scintillation $\beta$-spectrometer "Progress" with the plastic scintillation detector BDEB3-2U. The "Progress-5" software was used to analyze spectra in the range from $0.9 \mathrm{MeV}$ to $3.0 \mathrm{MeV}$, with the assumption that the sample contained ${ }^{\circ} \mathrm{K}$ and ${ }^{\circ} \mathrm{Sr}$ in equilibrium with ${ }^{\circ} \mathrm{Y}$ [2].

\section{RESULTS}

Probes from one sample of the reactor graphite were used in an experiment to verify the method for the determination of ${ }^{14} \mathrm{C}$ and $3 \mathrm{H}$. The mass of the probes varied to determine the minimum permissible mass, as the duration of the oxidation process depended on it. Changing probe mass from $1 \mathrm{~g}$ to $0.2 \mathrm{~g}$ reduced the process time from $3 \mathrm{~h}$ to $1 \mathrm{~h}$. The results showed good convergence (Table 1 ).
Table 1. Evaluation of the results' reliability

\begin{tabular}{|c|c|c|c|}
\hline No & $\begin{array}{c}\text { Mass of } \\
\text { graphite, } \mathbf{g}\end{array}$ & $\mathbf{1 4} \mathbf{C , ~ B q / g}$ & $\mathbf{3 H}, \mathbf{B q} / \mathbf{g}$ \\
\hline 1 & 0.208 & $1.8 \cdot 10^{3}$ & 140 \\
\hline 2 & 0.412 & $2.2 \cdot 10^{3}$ & 100 \\
\hline 3 & 0.600 & $2.1 \cdot 10^{3}$ & 150 \\
\hline 4 & 0.667 & $2.0 \cdot 10^{3}$ & 120 \\
\hline 5 & 0.802 & $1.5 \cdot 10^{3}$ & 140 \\
\hline 6 & 0.831 & $2.0 \cdot 10^{3}$ & 156 \\
\hline 7 & 1.01 & $2.1 \cdot 10^{3}$ & 90 \\
\hline
\end{tabular}

The method was used to analyze the irradiated graphite samples from the research reactor RFT (NRC "Kurchatov Institute") and the RBMK Leningrad nuclear power plant. The obtained results are presented in Table 2.

Table 2. Specific activity of radionuclides in irradiated reactor graphite, $\mathrm{Bq} / \mathrm{kg}$

\begin{tabular}{|c|c|c|c|c|}
\hline Sample & 137Cs & ${ }^{90} \mathrm{Sr}$ & ${ }^{14} \mathrm{C}$ & $\mathbf{3 H}$ \\
\hline $\begin{array}{c}\text { Graphite RFT } \\
\text { outside active } \\
\text { zone }\end{array}$ & \begin{tabular}{|l|}
$1.4 \cdot 10^{8}$ \\
$8.9 \cdot 10^{7}$ \\
$8.3 \cdot 10^{7}$ \\
\end{tabular} & $\begin{array}{l}2.2 \cdot 10^{7} \\
5.8 \cdot 10^{7} \\
8.5 \cdot 10^{6} \\
\end{array}$ & $\begin{array}{l}1.3 \cdot 10^{5} \\
6.1 \cdot 10^{5} \\
2.8 \cdot 10^{5} \\
\end{array}$ & $\begin{array}{l}5.0 \cdot 10^{4} \\
8.6 \cdot 10^{5} \\
5.2 \cdot 10^{4} \\
\end{array}$ \\
\hline $\begin{array}{c}\text { Graphite RFT } \\
\text { from active } \\
\text { zone }\end{array}$ & $1.5 \cdot 10^{8}$ & $1.5 \cdot 10^{8}$ & $1.0 \cdot 10^{7}$ & $3.2 \cdot 10^{7}$ \\
\hline $\begin{array}{c}\text { Graphite } \\
\text { LNPP } \\
\text { section } \\
15-30 \\
\end{array}$ & $3 \cdot 3 \cdot 10^{7}$ & $7 \cdot 7 \cdot 10^{6}$ & $1.2 \cdot 10^{9}$ & $2.1 \cdot 10^{7}$ \\
\hline $\begin{array}{c}\text { Graphite } \\
\text { LNPP } \\
\text { section } \\
62-64\end{array}$ & $3.1 \cdot 10^{5}$ & $1.8 \cdot 10^{6}$ & $8.8 \cdot 10^{8}$ & $7.0 \cdot 10^{6}$ \\
\hline $\begin{array}{c}\text { Graphite } \\
\text { LNPP } \\
\text { section } \\
55-54\end{array}$ & $3.1 \cdot 10^{5}$ & 40 & $1.2 \cdot 10^{9}$ & $5 \cdot 5 \cdot 10^{7}$ \\
\hline
\end{tabular}

Concentrations of ${ }^{14} \mathrm{C}$ and $3 \mathrm{H}$ in the irradiated graphite of the reactor RFT were insignificant except for those in the active zone. In the active zone, the concentrations of ${ }^{14} \mathrm{C}$ and $3 \mathrm{H}$ increased by more than two orders of magnitude up to $10^{7} \mathrm{~Bq} / \mathrm{kg}$ that corresponded to their activation nature. ${ }^{137} \mathrm{Cs}$ and ${ }^{90} \mathrm{Sr}$ are the main radionuclides contaminating the graphite of the research reactor RFT .In the samples of graphite taken at different layers of the graphite stack of the RFT reactor, concentrations of ${ }^{137} \mathrm{Cs}$ and ${ }^{90} \mathrm{Sr}$ vary slightly due to the accidents, which occur during the reactor function associated with the depressurization of fuel elements.

The results presented in Table 2 show that ${ }^{14} \mathrm{C}$ and $3 \mathrm{H}$ are the main contaminants of the irradiated graphite of the RBMK Leningrad NPP. At the same

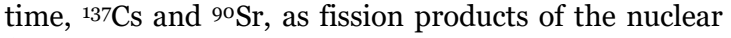
fuel, contribute a lot to the RBMK Leningrad NPP graphite contamination. 


\section{CONCLUSIONS}

1. The proposed method allows carrying out a rapid determination of ${ }^{14} \mathrm{C}$ concentration in the irradiated reactor graphite.

2. The radionuclides ${ }^{137} \mathrm{Cs}$ and ${ }^{90} \mathrm{Sr}$ determine the level of contamination of the RFT reactor's graphite.

3. Concentrations of ${ }^{14} \mathrm{C}$ and $3 \mathrm{H}$ in the irradiated graphite of the reactor RFT are insignificant except for the active zone.

4. ${ }^{14} \mathrm{C}$ and $3 \mathrm{H}$ are the main radionuclides contaminating the irradiated graphite of the RBMK Leningrad NPP.

Acknowledgement: We express gratitude to the staff of the IRMT NRC "Kurchatov Institute" for kindly providing the samples of irradiated graphite of the RBMK Leningrad NPP.

\section{REFERENCES}

1. Iu. Simirskii, A. Stepanov, I. Semin, A. Volkovich, "Reactor RFT Graphite Stack Spectrometric Investigation," in Proc. Int. Conf. Nuclear Fuel Cycle (GLOBAL 2017), Seoul, South Korea, 2017, A-042.

2. A. V. Stepanov, Yu. N. Simirskii, I. A. Semin, A. G. Volkovich, "Comprehensive Radiometric Investigation of MR Reactor Pool Water," Atom. Energy, vol. 117, no. 1, pp. 57 - 61, Nov. 2014. DOI: $10.1007 / \mathrm{s} 10512-014-9888-y$ 